\title{
Annual Cycle of the Density Field in Bass Strait*
}

\author{
P. G. Baines ${ }^{\mathrm{A}}$ and C. B. Fandry ${ }^{\mathrm{B}}$ \\ A Division of Atmospheric Physics, CSIRO, P.O. Box 77, Mordialloc, Vic. 3195. \\ B Australian Numerical Meteorology Research Centre, \\ P.O. Box 5089AA, G.P.O., Melbourne, Vic. 3001.
}

\section{Abstract}

A study of the density field in Bass Strait has revealed an annual cycle ranging from well-mixed to vertically stratified conditions. Historical data of $\sigma$, values have been converted into the potential energy, and monthly averages have been computed to show the seasonal variation of the stratification. Bass Strait is well mixed in winter but has some stratification during the rest of the year, largely controlled by surface heating and tidal stirring. The central part of Bass Strait is strongly stratified in late summer. The simple energy-budget model leading to the 'H/u$u^{3}$ criterion,' where $H$ is the depth and $u$ the tidal speed calculated from a numerical model, has been compared with the data and is successful in describing the onset of stratification in spring but not its break up in autumn. Contours of $\log _{10} H / u^{3}$ show maximum values in the same area as those of strongest stratification in the non-winter months.

\section{Introduction}

Recent work on the oceanic density fields on the European continental shelf [see Simpson et al. (1977) and references cited therein] and in the Bay of Fundy-Gulf of Maine (Garrett et al. 1978) has indicated that the density fields are largely controlled by the competing factors of surface heating (or cooling) on the one hand and the stirring forces of the tides on the other, with stirring by wind being a smaller factor. In both of these regions, the semidiurnal tides are not small. A central feature of this work has been the use of the ' $H / u^{3}$ criterion', where $H$ is the depth and $u$ the tidal speed, due to Simpson and Hunter (1974). This was derived by comparing the rate of production of potential energy due to surface heat flux with the rate of dissipation of tidal energy, and yields a convenient yardstick of the degree of vertical stratification. The criterion has also been compared successfully with data from Long Island Sound (Bowman and Esaias 1981) and from Cook Strait (Bowman et al. 1980).

In this paper, the application of these ideas to Bass Strait-a large shallow body of water, with the unusual characteristic that it has two extensive open boundaries that are contiguous with the deep $(4500 \mathrm{~m})$ ocean, to the east and west-is described. Semidiurnal tides dominate the motion during most of the year in Bass Strait, with tidal ranges up to $3 \mathrm{~m}$ occurring along the northern Tasmanian coastline. Tidal speeds of $0.5 \mathrm{~m} \mathrm{~s}^{-1}$ are not uncommon, with maximum tidal flows of $3 \mathrm{~m} \mathrm{~s}^{-1}$ occurring in some areas. Little is known of the properties of the density field and water mass of this area (vide Newell 1961; Godfrey et al. 1980). With the use of all the available historical density data, it is shown below that the stratification in Bass Strait

*This paper is dedicated to Mr B. V. Hamon in recognition of his important contribution to physical oceanography in Australia.

$0067-1940 / 83 / 010143 \$ 02.00$ 
appears to be largely controlled by a balance between surface heating and tidal stirring, with stirring by wind being of secondary importance. The simple energybudget model (e.g. Simpson and Bowers 1981), which leads to the $H / u^{3}$ criterion, has been used and shown to be generally consistent with the observations.

\section{Data and Procedure}

Most of the known data on the density field of Bass Strait were used in this study. The dates of stations extended back to 1940 and included some recent cruises in 1980 by the Marine Science Laboratories at Queenscliff, Victoria. The Victorian Institute of Marine Sciences supplied most of the archived data. The data set is not large, 409 stations in all, and the total for each month is as follows.

Month Jan. Feb. Mar. Apr. May June July Aug. Sept. Oct. Nov. Dec.
No. of

$\begin{array}{lllllllllllll}\text { data points } & 37 & 48 & 39 & 25 & 50 & 4 & 40 & 28 & 28 & 57 & 43 & 10\end{array}$

Depth contours for Bass Strait are shown in Fig. 1. The area of interest is the shallow continental shelf region with depth less than $100 \mathrm{~m}$.

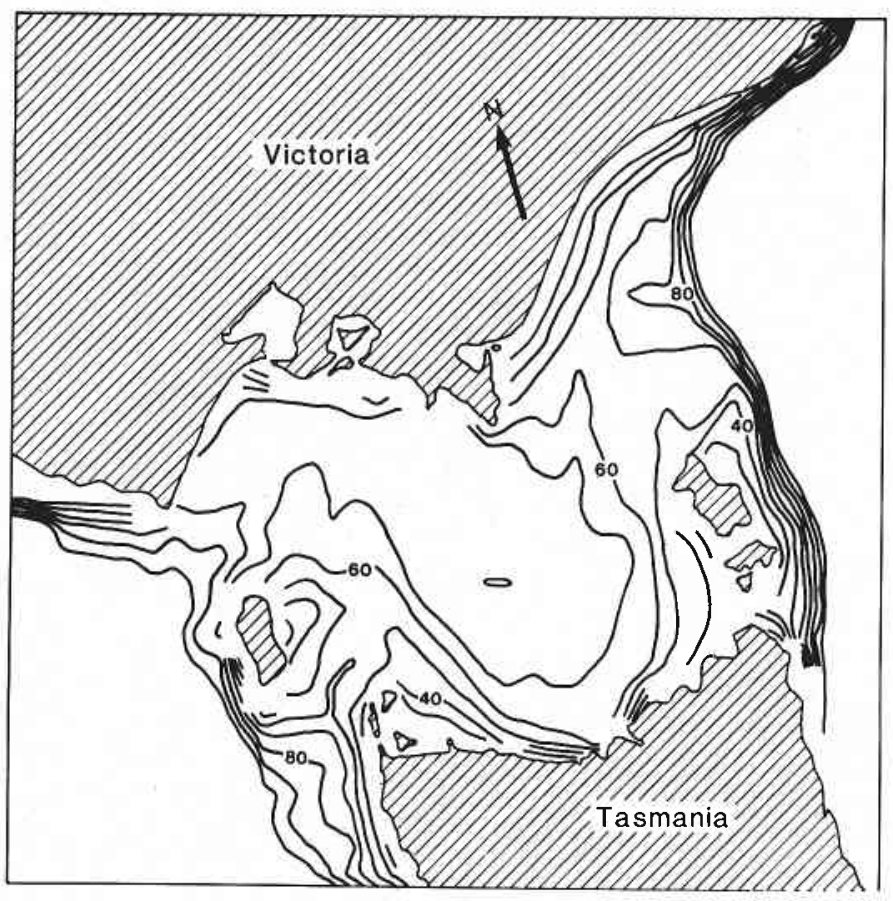

Fig. 1. Topography of Bass Strait. Depths are given in metres.

Following, for example, Simpson et al. (1977), we choose as a measure of the degree of stratification the quantity $\bar{V}$ defined by

$$
\bar{V}=\frac{1}{H} \int_{-H}^{0}(\rho-\bar{\rho}) g z \mathrm{~d} z
$$

where

$$
\bar{\rho}=\frac{1}{H} \int_{-H}^{0} \rho \mathrm{d} z .
$$

Here $\rho$ is the density of the water (defined in terms of $\sigma_{t}$ ), $H$ the total depth, $z$ the vertical coordinate with zero at the surface, and $g$ the acceleration due to gravity. Hence, $\bar{V}$ is the (depth-averaged) potential energy due to stratification (MKS units); it is zero for a uniformly mixed water column and negative if the water is 
stably stratified. At most stations, the water was sampled (temperature and salinity) at 10-m intervals (with occasional gaps). Intermediate values of $\rho$ were obtained by linear interpolation, except at the bottom and top where water below or above the end-point was assumed to have the same density as the water at the end-point.

\section{Results}

\section{Monthly Variations in Stratification}

Plots of $\log _{10}|\bar{V}|$ are shown in Fig. 2 for 9 months for which there are sufficient data to infer the overall pattern (the points for September are not well distributed and do not justify contouring). The dots denote data points. The plots were made by first interpolating the randomly spaced data points onto a rectangular grid. The value of $\bar{V}_{i}$ at the $i$ th grid point was obtained by first weighting the values of $\bar{V}_{j}$ by a Gaussian factor,

$$
w_{i j}=\exp \left[-\frac{1}{2}\left(r_{i j} / r_{\mathrm{m}}\right)^{2}\right]
$$

where $r_{i j}$ is the distance from the grid point $i$ to the data point $j$, and $r_{\mathrm{m}}$ is the mean value of the distance from each data point to its nearest neighbour; the weighted mean of these values then gives the grid-point value, i.e.

$$
\bar{V}_{i}=\frac{\Sigma_{j} w_{i j} \bar{V}_{j}}{\Sigma_{j} w_{i j}} .
$$

A conventional routine was then used to plot the contours from the grid values. The Bass Strait islands were ignored in the drawing of the contours.

As the distribution of data points shows, the data coverage is reasonably uniform, but some 'noise' is expected due to 'random' interannual fluctuations because of the rather limited data set. Hence, not very much can be inferred from the small-scale details. However, the pattern of the monthly variations is generally consistent, and this implies that some general conclusions can be drawn about the overall behaviour.

In regions where $\log _{10}|\bar{V}|<0$, shaded in the figure, the stratification is extremely weak so that the water may be effectively regarded as well mixed. An annual cycle is apparent in the data. Apart from regions near the edges, the water is fairly strongly stratified from November to April, particularly in the centre during February. At about the end of April, there is a rapid change to a well-mixed state over most of Bass Strait, which persists at least until September. The transition from the well-mixed state back to the stably stratified one apparently occurs much more gradually, from September to November (the large values of $\log _{10}|\bar{V}|$ at the east and west ends are due to the deepening of the water off the continental shelf and are not considered in this discussion). This contrast in the rate of change of stratification probably reflects the different time scales of convective overturning versus downward penetration of heat.

The boundaries between the well-mixed and stratified regions in some months suggest the existence of frontal regions. The data suggest the presence of fronts at each edge of Bass Strait during May-August; the eastern front is well known (Godfrey et al. 1980) but there is little direct evidence of a western one. Data from surface thermographs on commercial vessels crossing Bass Strait (from north to south) have not suggested any other major frontal feature (Godfrey et al. 1980), but several promising areas have not yet been explored. 
Fig. 2
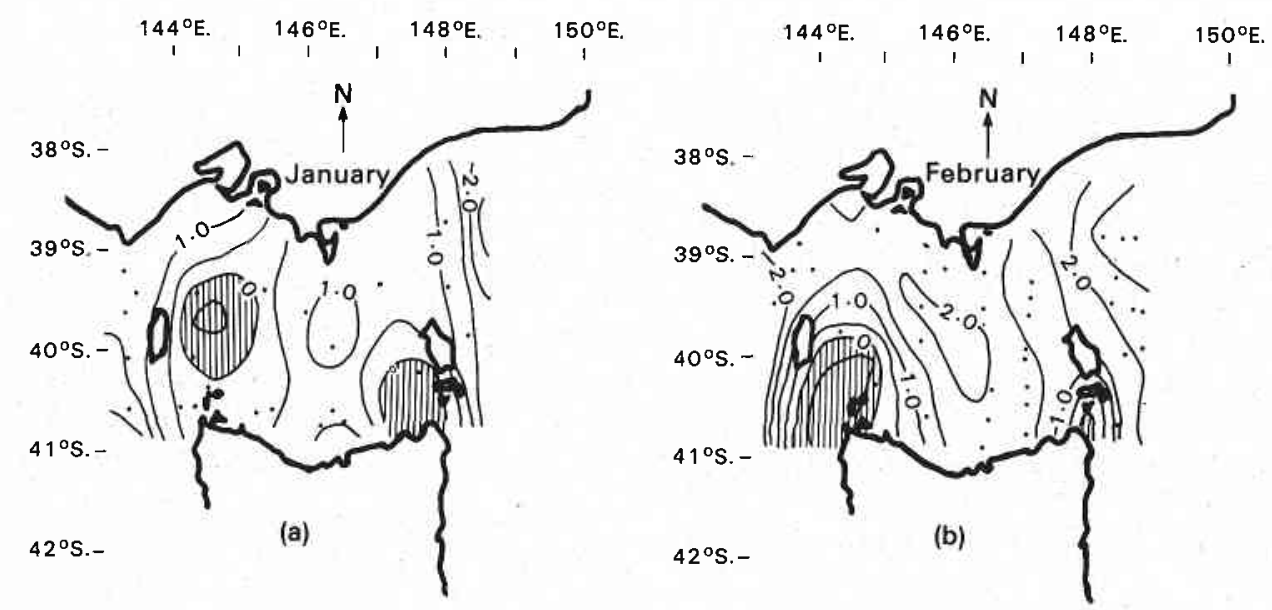

$144_{1}^{\circ} \mathrm{E}, \quad 146_{1}^{\circ} \mathrm{E} ., 148^{\circ} \mathrm{E} .,{ }_{1}^{150^{\circ} \mathrm{E} .}$

$144^{\circ} \mathrm{E}, \quad 146_{1}^{\circ} \mathrm{E}, \quad 148^{\circ} \mathrm{E}, \quad 150^{\circ} \mathrm{E}$.
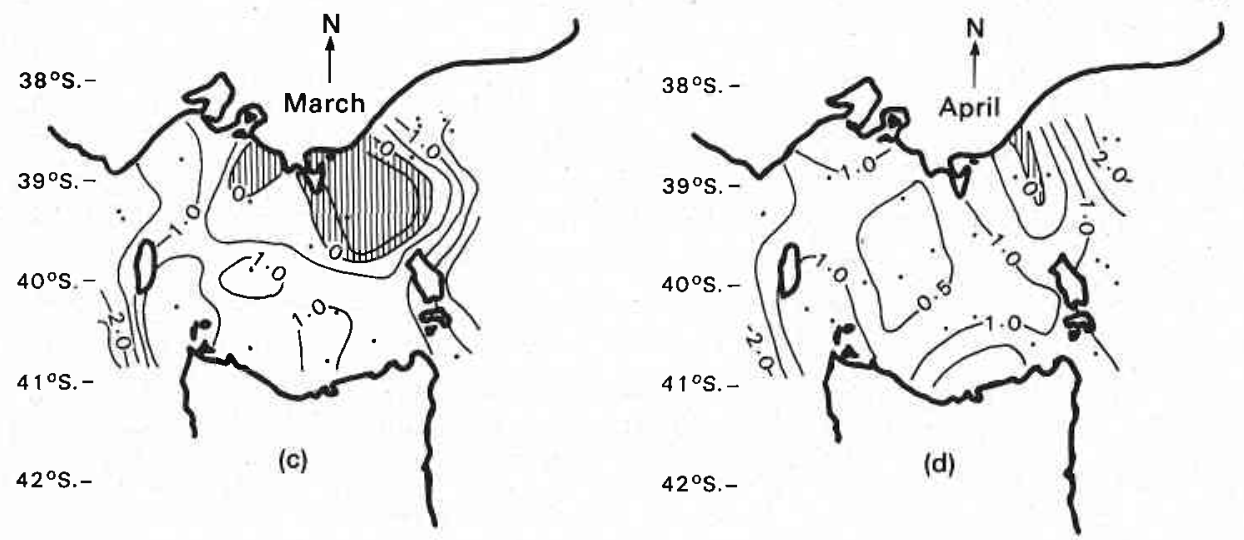

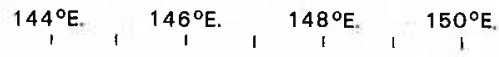

${ }_{1}^{144^{\circ} \mathrm{E} .},{ }^{146_{1}^{\circ} \mathrm{E} .},{ }^{148^{\circ} \mathrm{E} .},{ }^{150^{\circ} \mathrm{E} .}$
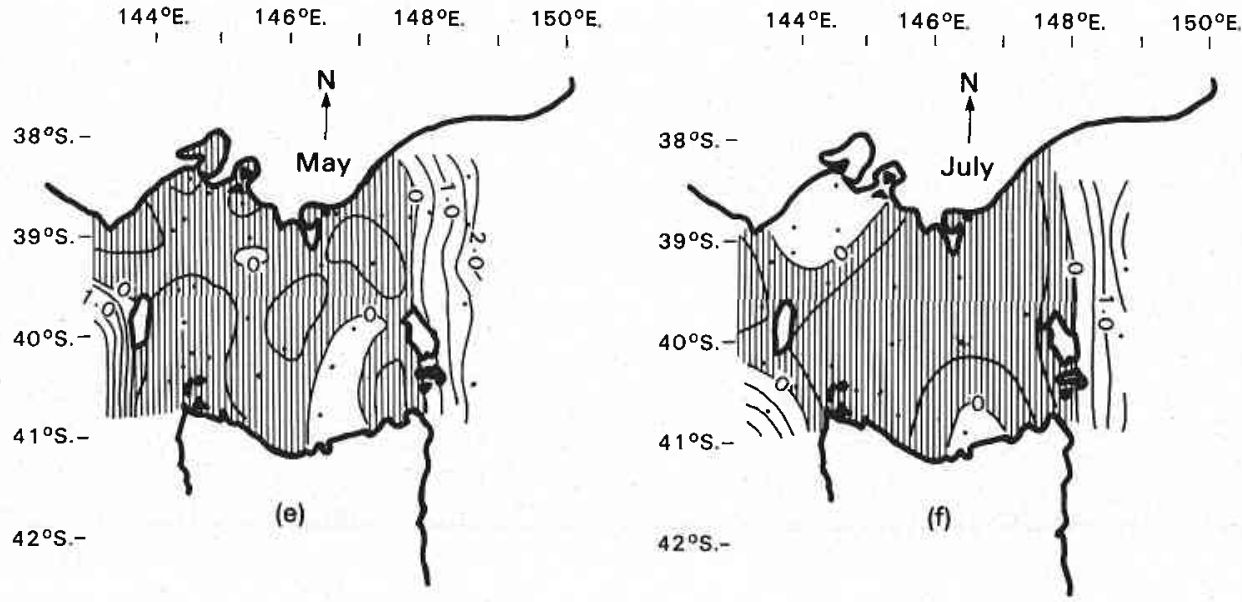
Fig. 2 (contd)
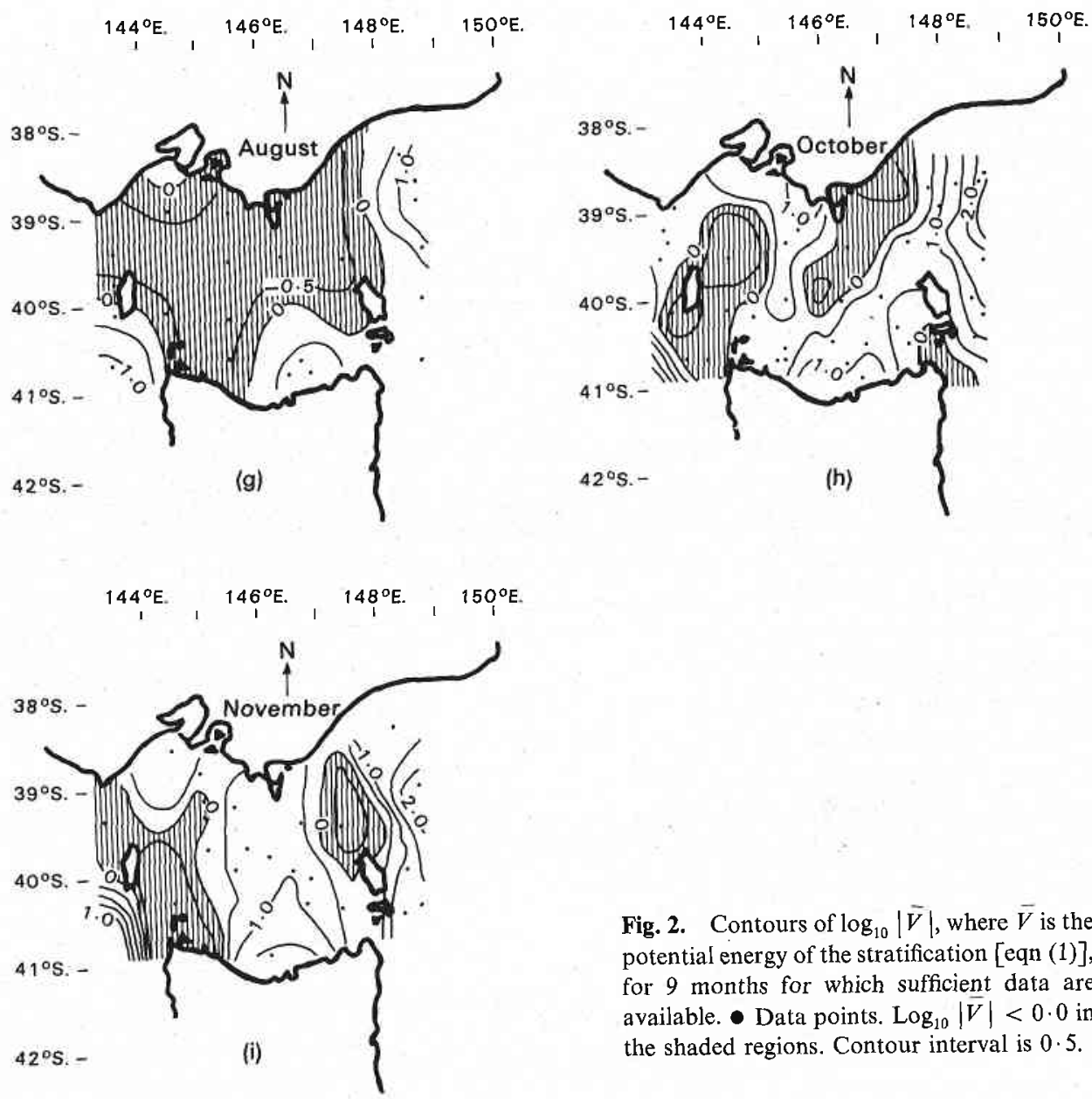

Fig. 2. Contours of $\log _{10}|\bar{V}|$, where $\bar{V}$ is the potential energy of the stratification [eqn (1)], for 9 months for which sufficient data are available. Data points. $\log _{10}|\bar{V}|<0.0$ in the shaded regions. Contour interval is 0.5 .

\section{Tidal Mixing and Surface Heating}

The equation for the time rate of change of the potential energy of a column of seawater of depth $H$, where horizontal advective effects are negligible, may be written (e.g. Simpson et al. 1978)

$$
H \frac{\mathrm{d} \bar{V}}{\mathrm{~d} t}=-\frac{\alpha \mathrm{g} \dot{Q}_{\mathrm{O}} H}{2 c_{\mathrm{p}}}+{ }_{\varepsilon} C_{\mathrm{D}} \rho \overline{u^{3}}+\delta k_{\mathrm{s}} \rho_{\mathrm{a}} \overline{W^{3}},
$$

where $\alpha$ and $c_{\mathrm{p}}$ are the volume expansion coefficient and the specific heat of seawater, respectively, $g$ is the acceleration due to gravity, $\dot{Q}_{\mathrm{O}}$ the rate of supply of heat to the water column, $C_{\mathrm{D}}$ the bottom drag coefficient, $k_{\mathrm{s}}$ the surface drag coefficient, $\rho_{\mathrm{a}}$ the density of air, and $u$ and $W$ are, respectively, the bottom water velocity and the wind velocity near the surface. The overbars denote time averaged over a suitable interval, principally the tidal period, and the dot denotes a time derivative. $\varepsilon$ and $\delta$ denote empirically determined efficiencies for bottom stirring and stirring by the wind, respectively. 
The first term on the right-hand side of equation (5) denotes the rate of increase of (negative) potential energy due to the surface heat flux, and the second and third denote losses due to stirring by the bottom and surface stresses. In this section, wind effects are omitted so that the last term is absent and $u$ denotes the tidal velocity. Heat storage in the sediments and ocean bottom are also neglected.

For the first term, the monthly heat flux has been estimated as follows. For each of the 9 months shown in Fig. 2, the heat-content values of each station with depth less than $100 \mathrm{~m}$ were calculated, and these values were then interpolated onto a grid using the procedure described in Monthly Variations in Stratification. These values were then integrated over Bass Strait to give the total heat content per unit area, and successive differences were then taken to give the nett heat fluxes over the monthly (or 2-monthly) intervals. The same calculation was carried out for the salinity, and the results are shown in Fig. 3. The salinity scale has been chosen to give the equivalent effect on the density to the temperature scale (approximately). Error bars are difficult to estimate, but the salinity variations are small and are probably not significant. For the temperature field, apart from the period from February to April, an annual cycle is apparent in the data. The behaviour in this 3 -month period is possibly due to an anomalous month (of the 44 stations with $H<100 \mathrm{~m}$ in February, 43 are from the year 1961, and of the 22 for April, 12 are from 1955). If these values are smoothed by taking $x_{i}$ (smoothed) $=0 \cdot 5\left[x_{i}+0 \cdot 5\left(x_{i-1}+x_{i+1}\right)\right]$, where $x_{i}$ denotes the value of $\dot{Q}_{\mathrm{O}}$ after the $i$ th month, the curve shown in Fig. 4 is obtained, and this curve will be taken as representing the annual cycle of heating for Bass Strait waters.

Also shown in Fig. 4 are the quarterly values (denoted by asterisks) for the nett downward radiative flux at the top of the atmosphere above Bass Strait, obtained from Stephens et al. (1981). The annual mean of this flux for the Bass Strait region is approximately zero, and the seasonal values are of comparable magnitude to those for the total heat flux to Bass Strait waters. The significance of this may be seen from the following equations. The time rate of change of the thermal energy $Q_{\mathrm{A}}$ and $Q_{\mathrm{O}}$ stored in the atmospheric and oceanic columns, respectively, may be expressed

$$
\begin{aligned}
& \dot{Q}_{\mathrm{A}}=N_{\mathrm{T}}-T_{\mathrm{B}}-\nabla \cdot \boldsymbol{F}_{\mathrm{A}}, \\
& \dot{Q}_{\mathrm{O}}=T_{\mathrm{B}}-\nabla \cdot \boldsymbol{F}_{\mathrm{O}},
\end{aligned}
$$

where $N_{\mathrm{T}}$ denotes the nett downward radiative flux at the top of the atmosphere, $T_{\mathrm{B}}$ the downward heat flux at the sea surface, and the divergences denote the horizontal heat flux out of the respective atmospheric and oceanic columns. In general, $\dot{Q}_{\mathrm{A}} \ll N_{\mathrm{T}}$, so that equation (6) becomes

$$
T_{\mathrm{B}} \simeq N_{\mathrm{T}}-\nabla \cdot F_{\mathrm{A}},
$$

and equation (7) becomes

$$
\dot{Q}_{\mathrm{O}} \simeq N_{\mathrm{T}}-\left(\nabla \cdot \boldsymbol{F}_{\mathrm{A}}+\nabla \cdot \boldsymbol{F}_{\mathrm{O}}\right)
$$

The result from Fig. 4 that $\dot{Q}_{\mathrm{O}} \simeq N_{\mathrm{T}}$ on a seasonal basis (although these quantities are by no means equal) implies that the horizontal divergences do not dominate the equation. This is in marked contrast to the situation over land where the ground storage is small and $N_{\mathrm{T}} \simeq \nabla . F_{\mathrm{A}}$, as has been shown by Hart (1983) in a heat-budget study of the atmosphere over part of Victoria and New South Wales. So far, few regional heat budgets over oceanic regions have been carried out, but it seems probable 
that the near equality of the seasonal values of $\dot{Q}_{\mathrm{O}}$ and $N_{\mathrm{T}}$ for Bass Strait is unusual; for instance, in the equatorial regions, the annual mean of $N_{\mathrm{T}}$ is large positive $\left(\sim 80 \mathrm{~W} \mathrm{~m}^{-2}\right)$ and in polar regions it is large negative $\left(\sim-80 \mathrm{~W} \mathrm{~m}^{-2}\right)$, whereas the (long-term) annual mean of $\dot{Q}_{\mathrm{O}}$ must be zero.
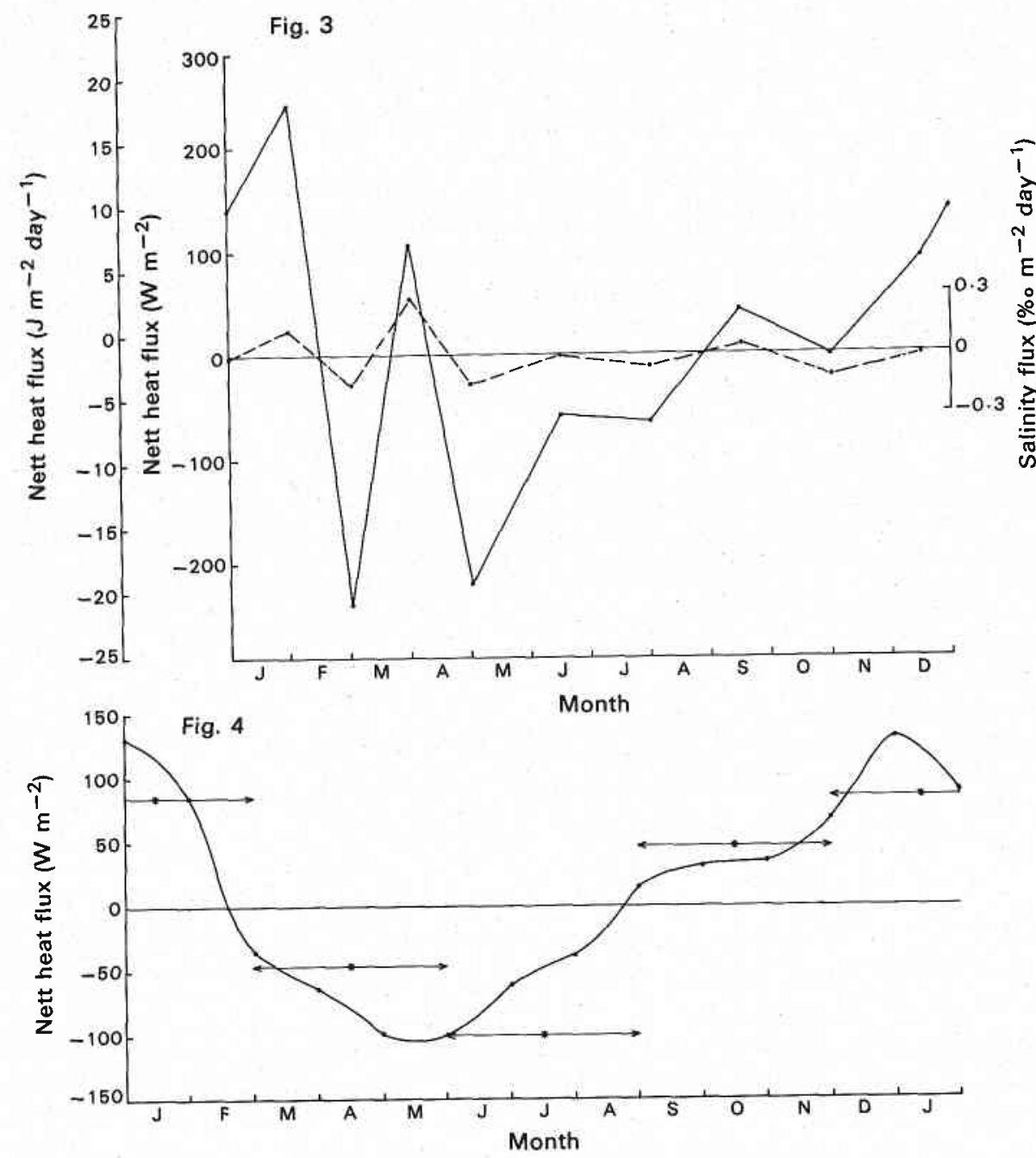

Fig. 3. Values of the nett heat flux $\dot{Q}_{\mathrm{O}}(-)$ and salinity flux $\dot{S}(---)$ to Bass Strait water obtained by taking monthly (or 2-monthly) differences in observed heat and salt content.

Fig. 4. Values for $\dot{Q}_{0}$ obtained from Fig. 3 by applying a simple smoothing procedure (see text). Asterisks denote quarterly values for the nett downward radiative flux at the top of the atmosphere for the Bass Strait region, obtained from Stephens et al. (1981).

Returning to equation (5), it can be seen from Fig. 4 that $\dot{Q}_{\mathrm{O}}$ is negative from March to August (inclusive), which is consistent with the steadily weakening stratification during March and April and the breakdown in May. The return of the heating part of the cycle in September is reflected in the increasing stratification evident in October. 
For the stratification to become established at all, it is necessary that

$$
\frac{\alpha g \dot{Q}_{\mathrm{O}} H}{2 c_{\mathrm{p}} \varepsilon C_{\mathrm{D}} \rho \overline{u^{3}}}>1 \text {. }
$$

With the values $\alpha=2.2 \times 10^{-4}\left({ }^{\circ} \mathrm{K}\right)^{-1}, c_{p}=3.99 \times 10^{3} \mathrm{~J} \mathrm{~kg} \mathrm{~m}^{-1}\left({ }^{\circ} \mathrm{K}\right)^{-1}$, $C_{\mathrm{D}}=2.5 \times 10^{-3}$ and $\varepsilon=0.0037$ (Simpson and Bowers 1981), this equation may be expressed as (with MKS units)

$$
\log _{10} \dot{Q}_{\mathrm{O}}>4 \cdot 55-\log _{10} H / \overline{u^{3}} \text {. }
$$

The tide in Bass Strait is dominated by the $\mathrm{M}_{2}$ component, but the very small number of observations of tidal currents prohibits the evaluation of the $H / u^{3}$ pattern directly from observations. Instead, the numerical model of tidal motion developed by Fandry $(1981,1982)$ is used, and contours of $R=\log _{10} H / \bar{u}^{3}$ calculated from this model are shown in Fig. 5. $R$ has minimum values at the eastern and western entrances and near

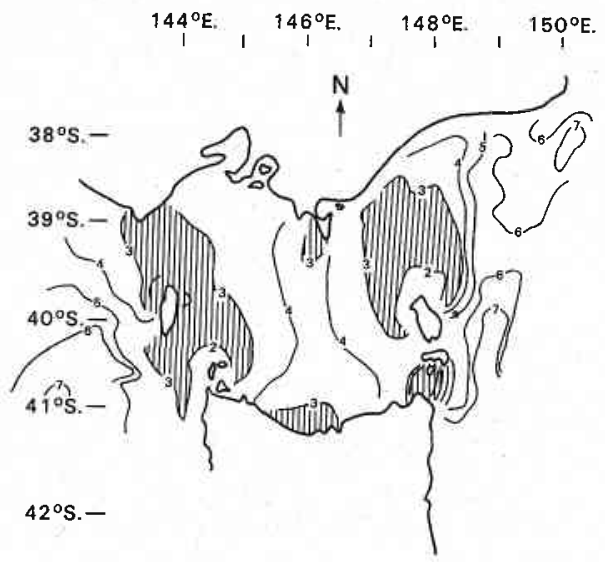

Fig. 5. Contours of $R=\log _{10}\left(H / \overline{|u|^{3}}\right)$, where $|u|$ is the semidiurnal tidal current speed, obtained from the model of Fandry (1982).

the islands, where $H$ is small and $u$ is large. High values of $R$ to the west and east are due to the very deep water off the continental slope and, as previously mentioned, are not relevant to this work.

After the onset of spring, from Fig. $4, \dot{Q}_{\mathrm{O}}$ assumes a fairly constant value of $\sim 30 \mathrm{~W} \mathrm{~m}^{-2}$ for approximately 2 months. With this value of $\dot{Q}_{\mathrm{O}}$, according to equation (11) stratification will occur if $R>3 \cdot 1$. From Fig. 5 it can be seen that, on the continental shelf, this is only the case in the centre of Bass Strait, and this is consistent with the observations in Fig. 2 for October and November. The maximum value of $\dot{Q}_{\text {o }}$ from Fig. 4 is $130 \mathrm{~W} \mathrm{~m}^{-2}$, and this implies that stratification will occur sometime during the summer if $R>2 \cdot 4$. This is satisfied over nearly all of Bass Strait, but only marginally so at the eastern and western entrances.

The cooling part of the cycle begins at the end of February but the stratification persists until May. The destratification process in autumn does not appear to be symmetric in time with regard to the spring onset, and it appears to occur all over Bass Strait in May rather than first at the edges where $R$ is smaller. The data are therefore consistent with the notion that the simple energy-balance model is capable of predicting the onset of stratification in broad terms but cannot describe the process of destratification. 


\section{Wind Effects}

Wind may affect the stratification in three ways, viz, (i) by influencing the surface heat flux, (ii) by mechanical stirring of the surface mixed layer and (iii) by bottom stirring due to wind-induced currents. (i) has already been accommodated in the previous section. (ii) is represented by the last term in equation (5). At present, the existing wind data for Bass Strait have not been compiled, and attention here will be restricted to representative conditions. Typical wind speeds are $5-10 \mathrm{~m} \mathrm{~s}^{-1}$ for the non-winter months and $20-40 \mathrm{~m} \mathrm{~s}^{-1}$ for the winter months. With the values $k_{s}=6.4 \times 10^{-5}$ and $\delta=0.023$ (Simpson and Bowers 1981), it is found from equation (5) for the above wind speeds, that stirring by wind is smaller than tidal mixing in the non-winter months, except possibly in the centre of Bass Strait, but is substantial in winter months.

With regard to wind-induced bottom stirring effects (iii above), during most of the year the wind-driven flow is smaller than the tidal flow (Fandry 1982). Typical tidal flows in Bass Strait are $0.4 \mathrm{~m} \mathrm{~s}^{-1}$, which is equivalent to wind-driven flows induced by winds of $20 \mathrm{~m} \mathrm{~s}^{-1}$. In non-winter months, typical wind-driven flows are less than $0.2 \mathrm{~m} \mathrm{~s}^{-1}$. Fig. 6 shows contours of $R$ for wind-driven flows induced by constant
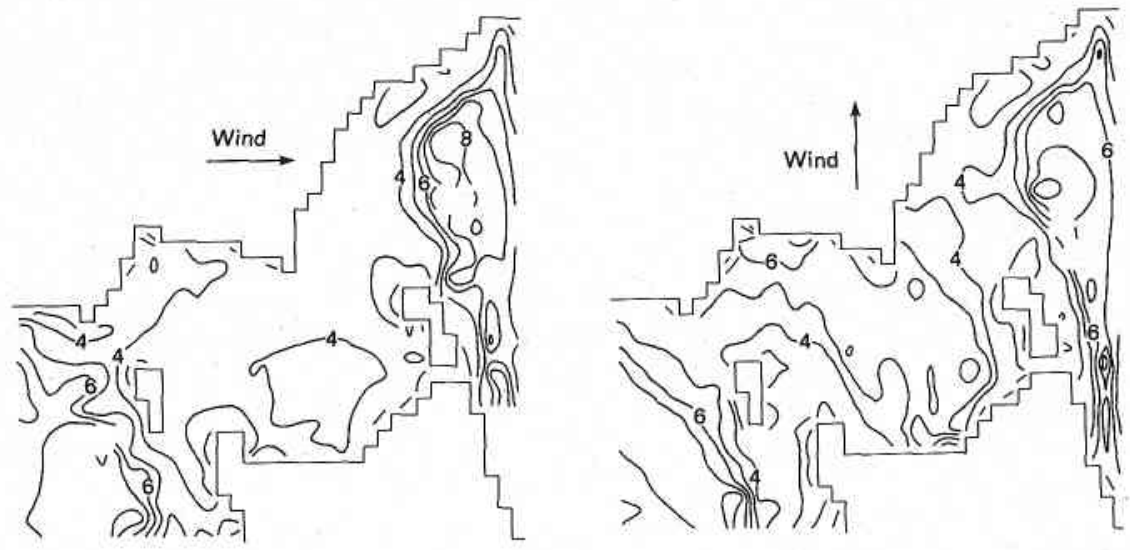

Fig. 6. Contours of $R$ where $|u|$ is the fluid speed resulting from a constant uniform westerly $(a)$ and southerly $(b)$ wind of $18 \mathrm{~m} \mathrm{~s}^{-1}$ (wind stress of $1 \mathrm{~N} \mathrm{~m}^{-2}$ ), as obtained from the model of Fandry (1982).

uniform westerly and southerly wind fields of $18 \mathrm{~m} \mathrm{~s}^{-1}$. Contour values are higher than the equivalent tidal case shown in Fig. 5 and would be much higher for weaker winds. Only during the winter months, when prevailing wind speeds of $20-40 \mathrm{~m} \mathrm{~s}^{-1}$ exist, will wind-driven flows be important in mixing.

The above considerations indicate that wind effects are not negligible, particularly in winter, and it is probable that wind contributes to the destratification process. The good correlation between Figs 2 and 5, however, indicates that stratification is largely controlled by surface heating and tidal stirring for most of the year.

\section{Discussion}

We have shown that the stratification of Bass Strait appears to be largely controlled by the competing processes of surface heating and tidal stirring, although the magnitudes of effects of stirring by wind have not been fully quantified. The 
simple energy-budget model satisfactorily describes the onset of stratification in spring but not its break-up in autumn. The reason for the latter probably involves additional physics of the effects of stratification on mixing processes. Simpson and Bowers (1981) use a 'variable efficiency' model to accommodate this behaviour. A different approach based on Froude-number closure has been developed by the first author and P. C. Manins and will be reported elsewhere.

On the basis of the above, the seasonal variations in the horizontal and vertical structure of the Bass Strait waters may be inferred. Under the influence of the prevailing westerlies during the winter months, fluid parcels entering the western end of Bass Strait pass through a region where they are well mixed throughout the depth. They continue to be mixed with neighbouring parcels as they traverse the entire Strait, which will generally take about 10-20 days. However, in summer, when tidal flows dominate the motion, residence times are much longer, with the result that fluid parcels entering the strongly stratified region in central Bass Strait are confined to a particular depth for several months. Due to the residual motion, these parcels will eventually exit on the eastern side after passing through the tidally stirred regions to the north and south of Flinders Island where they will again be mixed with their vertical neighbours. These distinct patterns of movement during winter and summer may well have significance for biological and geological processes.

\section{Acknowledgments}

The authors are grateful to the Victorian Institute of Marine Sciences for supplying most of the data in compact form, to Dr Colin Gibbs for supplying his most recent measurements, to Mr Andrew Mattingly for computing the $\bar{V}$-values and contouring the results, and to Dr John $H$. Simpson for comments on an early version of the manuscript.

\section{References}

Bowman, M. J., and Esaias, W. E. (1981). Fronts, stratification and mixing in Long Island and Block Island Sounds. J. Geophys. Res. 86, 4260-4.

Bowman, M. J., Kibblewhite, A. C., and Ash, D. E. (1980). M tidal effects in greater Cook Strait, New Zealand. J. Geophys. Res. 85, 2728-42.

Fandry, C. B. (1981). Development of a numerical model of tidal and wind-driven circulation in Bass Strait. Aust. J. Mar. Freshw. Res. 32, 9-29.

Fandry, C. B. (1982). A numerical model of the wind-driven transient motion in Bass Strait. J. Geophys. Res. 87, 499-517.

Garrett, C. J. R., Keeley, J. R., and Greenberg, D. A. (1978). Tidal mixing versus thermal stratification in the Bay of Fundy and Gulf of Maine. Atmos.-Ocean 16, 403-23.

Godfrey, J. S., Jones, I. S. F., Maxwell, J. G., and Scott, B. D. (1980). On the winter cascade from Bass Strait into the Tasman Sea. Aust. J. Mar. Freshw. Res. 30, 275-86.

Hart, T. L. (1983). Large-scale atmospheric flux and flux divergence over south-east Australia. Aust. Meteorol. Mag. (In press.)

Newell, B. S. (1961). Hydrology of the south-east Australian waters. CSIRO, Div. Fish Oceanogr., Tech. Pap. No. 10.

Simpson, J. H., Allen, C. M., and Morris, N. C. G. (1978). Fronts on the continental shelf. J. Geophys. Res. 83, 4607-14.

Simpson, J. H., and Bowers, D. (1981). Models of stratification and frontal movement in shelf seas. DeepSea Res. 28A, 727-38. 